\title{
Contact lens prescribing in Canada 2011
}

\author{
BY DEBORAH JONES 1,2 FCOptom, \\ DipCLP, FAAO; CRAIG A WOODS $2,3 \mathrm{PhD}$, \\ MCOptom, FAAO, FACO; \\ NATHAN EFRON ${ }^{4}$ PhD, DSC, FAAO; \\ PHILIP MORGAN ${ }^{5}$ PhD, MCOptom, \\ FAAO, FBCLA
}

\section{Introduction}

Tor the past 12 years, the International Contact Lens Prescribing Survey Consortium has sent surveys to a selection of

\section{LA PRESCRIPTION DES LENTILLES DE CONTACT AU CANADA, 2011 RÉSUMÉ}

Depuis 12 ans, une enquête a lieu chaque année au Canada pour recueillir des données sur les lentilles de contact que prescrivent les praticiens. On a demandé aux praticiens de fournir des renseignements sur les 10 premiers patients à qui ils avaient ajusté des lentilles de contact tout de suite après avoir reçu le formulaire d'enquête. Au total, 121 formulaires remplis présentant 1184 patients ayant reçu des lentilles de contact ont été renvoyés.

Parmi les patients pour lesquels des lentilles de contact ont été prescrites, les résultats indiquent que la majorité d'entre eux ont reçu des lentilles souples. La modalité préférée était le remplacement mensuel, et plus de $67 \%$ des lentilles souples étaient fabriquées de silicone-hydrogel. La majorité des lentilles rigides ont été prescrites pour le jour, puisque leur port pendant la nuit semble surtout convenir à des traitements d'orthokératologie. Les praticiens recommandent des solutions polyvalentes à la plupart de leurs patients ayant des lentilles souples (85,6\%).

Mots clés : souples, rigide, habitudes de prescription des lentilles de contact
Canadian optometrists in order to collect information on the contact lenses they fit and basic demographic data of the patients. Canada is one of about 40 countries that contributes to the global study and while annual reviews of the study data are presented, information published for any one market is limited due to the size of the dataset. ${ }^{1}$ This manuscript presents a more detailed analysis on the Canadian market for 2011.

\section{Methods}

In early 2011, surveys were sent to 1,000 randomly selected Canadian optometrists to collect information

\section{ABSTRACT}

The annual survey to collect data on the contact lens prescribing preferences of practitioners has continued for 12 years in Canada. Practitioners were surveyed for information on the first 10 patients they fitted with contact lenses immediately after receipt of said survey. A total of 121 completed surveys were returned, detailing contact lens fittings for 1,184 patients.

Of the patients fitted with contact lenses, the results indicated that the majority were prescribed soft lenses. The preferred modality was monthly planned replacement and over 67 per cent of the soft lens fits were made of silicone hydrogel materials. Of the rigid lens fits, the majority were prescribed for daily wear, as the overnight use of rigid lenses appears to be mainly for orthokeratology. Practitioners are recommending multipurpose solutions for the majority of their soft lens patients (85.6\%).

Key words: soft, rigid, contact lens prescribing habits
1 School of Optometry, University of Waterloo, 200 University Avenue West, Waterloo, Ontario, Canada N2L 3 G1

2 Centre for Contact Lens Research, School of Optometry, University of Waterloo, 200 University Avenue West, Waterloo, Ontario, Canada N2L 3 G1

3 School of Medicine (Optometry), Faculty of Health, Deakin University, 75 Pigdons Rd, Waurn Ponds, 3216 Australia

4 Institute of Health and Biomedical Innovation, and School of Optometry, Queensland University of Technology, 60 Musk. Avenue, Kelvin Grove, Queensland 4059, Australia

5 Eurolens Research, The University of Manchester, Moffat Building, P.O. Box 88, Manchester M60 1QD, United Kingdom

on contact lens fittings. Each optometrist was asked to provide information on the first 10 lens fittings undertaken following receipt of the survey form. Information collected was: date of fitting, gender and age of patient, whether it was a new or a refit, the lens material, lens design and replacement frequency, how often the lenses were intended to be worn, whether prescribed for daily or extended wear, and information on the lens care system prescribed. The survey format has been consistent for all 12 years of data collection. Each fitting was weighted, based on the number of lenses fit per year by the practitioner (based on the date information on the form). This means that data generated by practitioners who conducted many contact lens fittings were afforded a higher weight than those performing fewer fittings. 


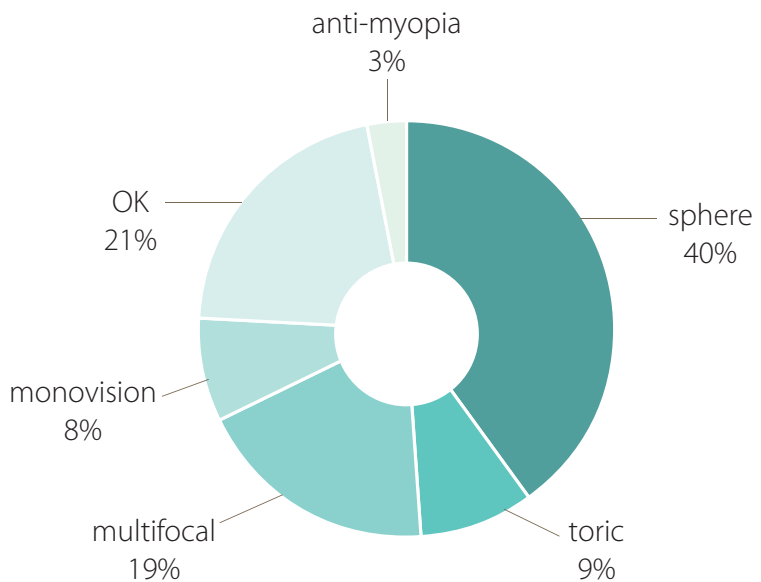

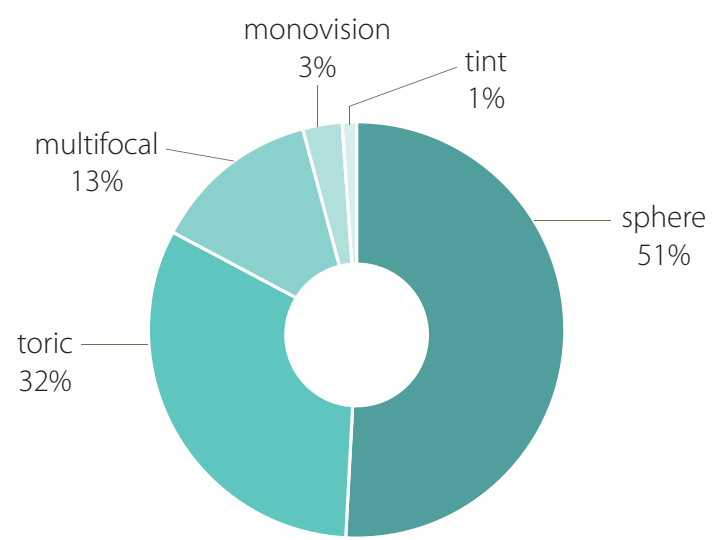

\section{Results}

Data from a total of 1,184 contact lens fittings were collected during the 2011 survey from the 121 surveys returned.

\section{Demographics}

The mean age of all persons fit with contact lenses was 34.9yrs ( \pm 15.2$)$ with females being slightly older than males (35.5yrs \pm 15.0 vs $33.5 \mathrm{yrs} \pm 15.5)$. More females were fitted with lenses than males $(71 \%$ vs $29 \%$ ). The majority of patients $(86 \%)$ were wearing their lenses on a full-time basis (7 days-a-week)

The majority of lenses fitted were as refits rather than new fits $(68 \%)$, and as would be expected, overall the majority of lenses prescribed were soft lenses $(92.9 \%)$.

GP lenses were mostly used to refit existing patients compared to new lens users ( $9.1 \%$ vs $2.9 \%)$. GP lenses are rarely fit as a first lens of choice - only 7.1 per cent of the overall fits were GP fits. Whether new or a refit, the majority of GPs appear to be prescribed as specialty lenses: 21 per cent for orthokeratology $(\mathrm{OK})$ and even 3 per cent for myopia control (Figure 1).

\section{Soft lenses}

\section{Soft lens designs}

The majority of soft lenses prescribed are spherical lenses followed by toric and multifocals (Figure 2).

\section{Soft lens replacement frequency}

Analysis of the replacement frequency of soft contact lenses reveals that conventional (non-planned replacement) are rarely fit (just 1.1\% of the total number of soft lenses). This is a smaller proportion than GP lenses. The majority of lenses being fit are on a monthly replacement modality, this is the same for new and refits (Figure 3).

\section{Soft lens materials}

Silicone hydrogels continue to be the material of preference for soft contact lenses $(67.7 \%$ of lenses fit) (Figure 4).

\section{Lens modality}

Extended wear lenses continue to be prescribed in limited numbers, accounting for only 3.5 per cent of all soft lens fittings. The higher proportion of extended wear lens fittings are refits as opposed to new fits $(4.6 \%$ vs $1.4 \%)$. Silicone hydrogel remains the material of choice for the extended wear modality (95.1\%).

\section{Lens care systems}

Multipurpose care systems dominate prescribed solutions (85.6\% of fits), with hydrogen peroxide accounting for 14.4 per cent of the market.

\section{Discussion}

It has been five years since we last reported on Canadian results from this ongoing annual international prescribing survey. ${ }^{2}$ A comparison to the results published in 2006 is summarized below (Table 1).

The age of the patients fit in 2011 are slightly older (34.9yrs vs 31.3yrs) and there are more females than in $2006(71 \%$ vs $67.3 \%)$. 
Figure 3 - Distribution of the replacement cycle for soft contact lenses

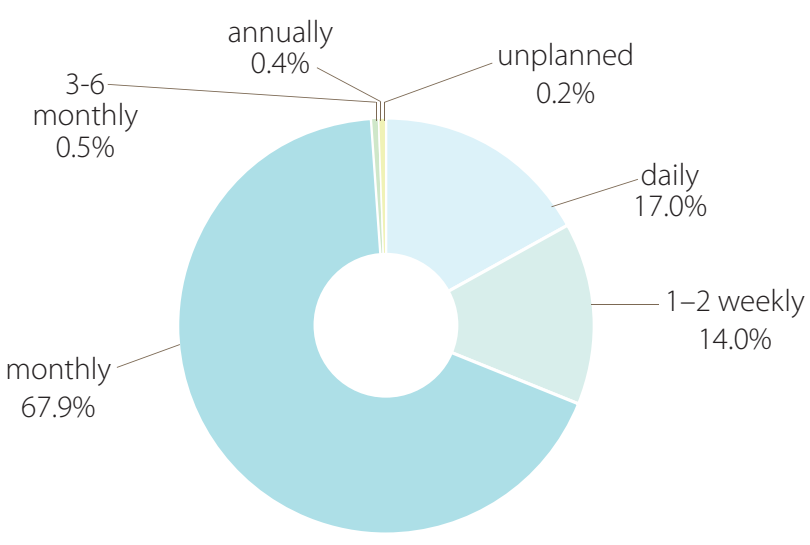

Figure 4 - Distribution of lens materials for soft lenses

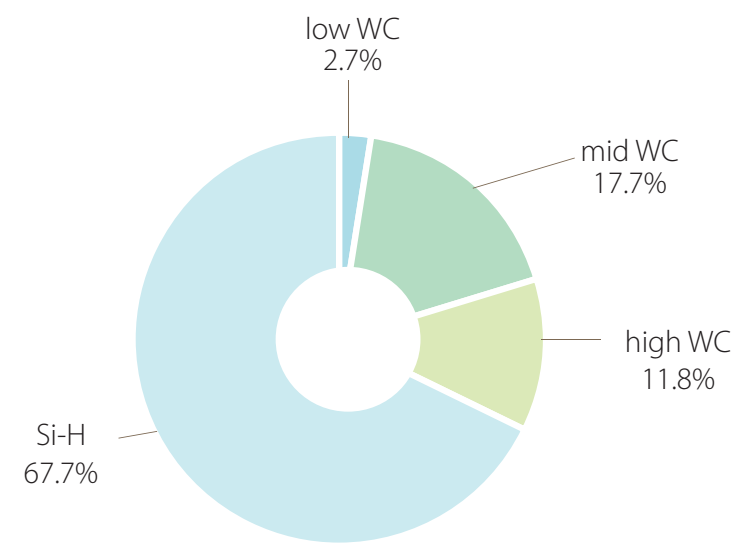

Table 1: Summary of some of the results published by Jones and Woods $2006^{2}$

\begin{tabular}{|l|l|}
\hline Mean age (yrs) & $31.3 \pm 13.9$ \\
\hline Gender (\%) & Female 67.3, Male 32.7 \\
\hline Lens type (\%) & Soft 92.7, GPs 7.1 \\
\hline Fit (\%) & New 35.0, Refit 65.0 \\
\hline $\begin{array}{l}\text { Planned replacement } \\
\text { frequency (\%) }\end{array}$ & Monthly 71, 2-week 18.4, daily disp. 6.1, non-planned 4.5 \\
\hline Soft lens material (\%) & LWC 7.4, MWC 41.8, HWC 11.0, Silicon hydrogel 39.8 \\
\hline Soft lens designs (\%) & Spherical 59.5, toric 28.5, multifocal 9.7, tint 2.3 \\
\hline Extended wear (\%) & $\begin{array}{l}\text { New 4.8, refits 10.0 } \\
\text { Hydrogel 3.8, Silicon hydrogel 96.2 }\end{array}$ \\
\hline GP lens design (\%) & $\begin{array}{l}\text { Spherical 36.0, toric 11.3, multifocal 10.7, orthokeratology 35.9, other } \\
10.6\end{array}$ \\
\hline Lens care (\%) & MPS 93.8, Peroxide 6.2 \\
\hline
\end{tabular}

The GP lens market appears unchanged and remains at 7.1 per cent of the overall market share. Orthokeratology has reduced slightly $(21 \%$ vs $35.9 \%$ ) and multifocals increased $(19 \%$ vs $11.3 \%)$ and interestingly some practitioners now report using these lenses for myopia control, a new aspect for lens use since 2006.

For soft lenses, multifocal designs have increased in use from just under 10 per cent to 13.7 per cent of the overall lens market. Monthly replacement continues to be the preferred modality, although it would appear the use of daily disposable lenses has increased $(14.0 \%$ vs $6.1 \%)$. Silicone hydrogel materials now have the largest share of the market at 67.7 per cent, in 2006 mid water content materials and silicone hydrogel material were being fit in equal shares. Only 1.1 per cent of soft lenses are now prescribed with a replacement schedule longer than one month compared to 4.5 per cent in 2006.

The market share for extended wear has decreased from 10 per cent of refits to 4.6 per cent and from 4.8 per cent to 1.4 per cent of new fits. This suggests that extended wear modality may be recommended for very specific circumstances only.

While lens care is dominated by multipurpose care systems, hydrogen peroxide based systems with a 14.4 per cent share is high in comparison to other countries and represents an increase compared to 2006.

\section{References}

1 Morgan PB, Woods CA, Tranoudis Y, Helland M, Efron N, Grupcheva CN, Jones D, Tan KO, Pesinova A, Santodomingo J, Malet F, Raguz H, Erdinest N, Hreinsson HI, Itoi M, Chu BS, Bendoriene J, van der Worp E, Awasthi S, Lam W, Gonzalez-Meijome JM, Radu S, Belousov V, Gustafsson J, Silih MS, Hsiao J and Nichols J (2011) International Contact Lens Prescribing in 2010. Contact Lens Spectrum 25(1): 30-35.

2 Jones DA and Woods CA. (2006) "Contact lens prescribing in Canada 2006." Canadian Journal of Optometry, 68(6) 231-237. 